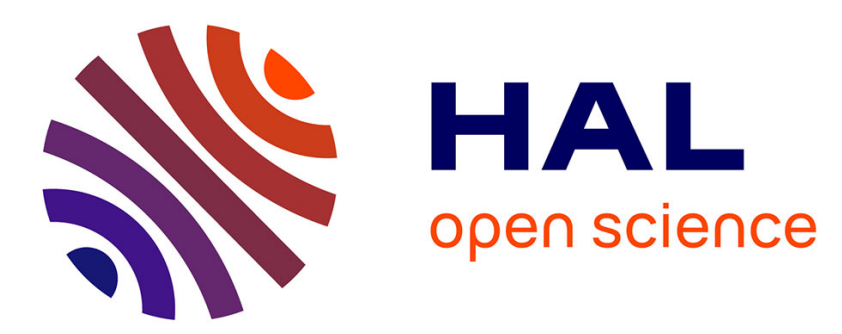

\title{
Design of Transplanting Mechanism with B-Spline Curve Gear for Rice Pot Seedling Based on UG
}

\author{
Yanjun Zuo, Huixuan Zhu, Peng Cao
}

\section{To cite this version:}

Yanjun Zuo, Huixuan Zhu, Peng Cao. Design of Transplanting Mechanism with B-Spline Curve Gear for Rice Pot Seedling Based on UG. 8th International Conference on Computer and Computing Technologies in Agriculture (CCTA), Sep 2014, Beijing, China. pp.226-232, 10.1007/978-3-319-196206_28. hal-01420236

\section{HAL Id: hal-01420236 \\ https://hal.inria.fr/hal-01420236}

Submitted on 20 Dec 2016

HAL is a multi-disciplinary open access archive for the deposit and dissemination of scientific research documents, whether they are published or not. The documents may come from teaching and research institutions in France or abroad, or from public or private research centers.
L'archive ouverte pluridisciplinaire HAL, est destinée au dépôt et à la diffusion de documents scientifiques de niveau recherche, publiés ou non, émanant des établissements d'enseignement et de recherche français ou étrangers, des laboratoires publics ou privés. 


\title{
Design of Transplanting Mechanism with B-Spline Curve Gear for Rice Pot Seedling Based on UG
}

\author{
Yanjun Zuo ${ }^{1, \mathrm{a}}$, Huixuan $\mathrm{Zhu}^{1, \mathrm{~b}}$, Peng $\mathrm{Cao}^{2, \mathrm{c}}$ \\ ${ }^{1}$ College of Engineering, Northeast Agricultural University, Harbin 150030, China; ${ }^{2}$ the 49th \\ Institute of China Electronics Technology Group Corporation, Harbin 150001, China; \\ a42648135@qq.com, b108091835@qq.com, ${ }^{\mathrm{c}} 36125922 @ q q . c o m$,
}

\begin{abstract}
In allusion to the existing rice pot seedling transplanter exists the defects of complex structure, high cost and low efficiency, the transplanting mechanism with $b$-spline curve gear for rice pot seedling was designed based on parametric modeling software UG NX 8.0. Firstly, the 3-D models of part were built, and then assembled. Secondly, the interference detection of assembly model was done. Finally, relevant 2-D engineering drawings were generated for manufacture. It is provides the reference for the design of rice pot seedling transplanter, and preparation for further simulation and analysis with softwares of Adams and Ansys.
\end{abstract}

Keywords: Rice pot seedling transplanting, B-Spline, UG, Virtual design

\section{Introduction}

Rice is one of the main food crops. and perennial planting area is about 30 million $\mathrm{hm} 2$ in China. The area account for national grain and world's rice planting areas are about $30 \%$ and $20 \%$, it only less than India and is the second largest in the world[1-2]. Therefore, our rice production has a pivotal position to food security not only for China but also for world. There are two modes of rice planting (direct seeding and transplanting) at present[3], but the Asia is given priority to rice seedling transplanting, the mechanization levels of Japan and Korea are highest and more than 98\% during Asia. The cultivation mode of rice transplanting is also divided seedling transplanting and pot seedling transplanting, comparing with seedling transplanting, the pot seedling transplanting has the advantages of seedling no hurting and no need recovering, production increasing and so on[4]. Since Japan invents the first transplanter for rice pot seedling in 1975, each large agricultural machinery company has producted their own models in succession, such as Yanmar, Iseki and so on. The material structure and processing technology have improved through the forty years development, but the its basic structure and working principle are still the same[5-10]. The transplanting machines of rice pot seedling use 3 devices to achieve the 3 actions of taking, transportation and planting separately, which gives rise to complex

* The paper is supported by the National Natural Science Fund Projects (Project number is 51175073), the Special Fund for Agro-scientific Research in the Public Interest (Project number is 201203059-01), the Northeast Agricultural University Doctor Startup Fund (Project number is 2012CRB56). 
structure, high cost and low efficiency, so the promotion area is limited[7,11-12]. The rice transplanter is main except rice pot seedling transplanting machine with double cranks, which is invented by Zhao Yun et al. The double cranks transplanting machine can use a mechanism to achieve 3 actions orderly for rice pot seedling, has relatively simple mechanism, but the disadvantages of large vibration and low efficiency are existent because of the characteristics of bar mechanism[13]. Therefore, the study on transplanting mechanism for rice pot seedling to efficient, light simplified and full-automatic, is very necessary.

In the study, UG NX 8.0 was applied for the design of transplanting mechanism with b-spline curve gear for rice pot seedling. The 3-D models of each part can be built and assembled easily, and interference detection of assembly models was done through the software. Therefore, virtual design can promoted standardization, normalization and serialization to physical prototype based on virtual manufacturing, assembly and test.

\section{Characteristics of UG NX 8.0}

Software of UG NX 8.0 is developed by SIEMENS, it is a flagship digital software for solution of NX. The software is comprehensive 3-D modeling software which gathers CAD, CAE and CAM, it sets up a new standard for machinery industry and is favoured by insider. In order to meet the requirements of users which can develop new product quickly, UG has more extensive product design module, such as modeling, simulation, assembly, bending and so on, and also has high performance of charting capability, so it is used widely in machinery, automobile and other manufacturing industries. In addition, UG can realize seamless joint with other virtual simulated softwares, such as Adams and View 2010, the model that is built in UG, can be operated directly after import[14].

\section{Results and Discussion}

\subsection{Working Principle}

The sketch of transplanting mechanism for rice pot seedlings is shown in figure 1, it is composed by transmission component with non-circular gear and transplanting component. The sun gear, middle gear and planet gear are non-circular gear. Planet carrier and sun shaft are solid joint, planet gear and transplanting arm(including cam, shifting fork, spring, spring place, seedling-pushing rod and seedling clip) are solid joint. Power income from sun shaft, planet carrier rotates uniformly, transplanting arm rotates reversely through middle gear, shifting fork is swaied by combined effect of cam and spring, the movement of seedling-pushing rod is formed by sway of shifting fork, the open and close of seedling clip are realized by movement of seedling-pushing rod. The whole transplanting process is achieved for rice pot seedling by the above actions. 

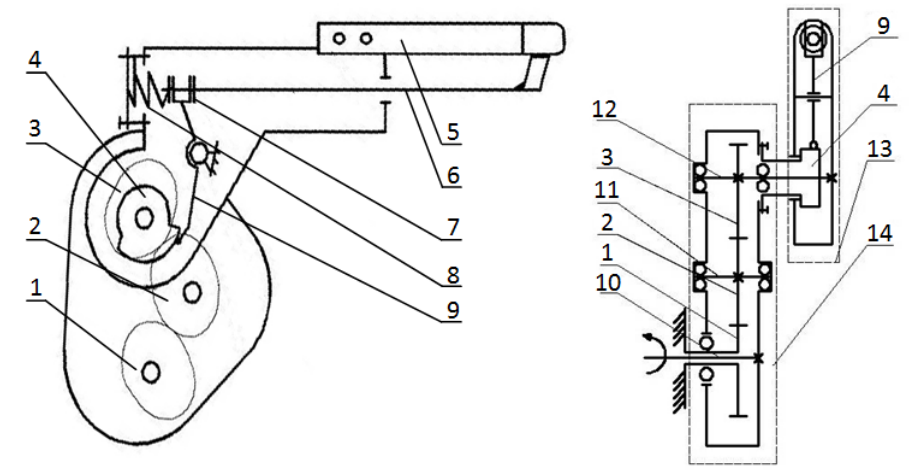

Fig. 1. The sketch of transplanting mechanism for rice pot seedlings 1. Sun gear 2. Middle gear 3. Planet gear 4. Cam 5. Seedling clip 6. Seedling-pushing rod 7. Spring place 8. Spring 9. Shifting fork 10. Sun shaft 11. Middle shaft 12. Planet shaft 13. Transplanting arm 14. Planet carrier

\subsection{Part Design}

The characteristics of criterion, voxel and basic shape design that were needed, could be built by 3-D capabilities in UG, such as base level, base coordinate, sphere, cylinder, square body, cone, stretching, rotating, draft, and slightly, convex platform, slotting and so on. Because the pitch curve of non-circular gear was irregular, the pitch curve was imported using interface of UG, and then stretched. The 3-D model of non-circular gear was obtained as shown in figure $2 \mathrm{a}$, the other five more important or distinctive parts were all simple, the 3 -D modeling process was not need to special instruct, the models were shown in figure 2.

\subsection{Assembly Design}

Based on section of 3.2, using the assembly module which is the built-in modules of UG, the assembly was done through adding the relevant constraints. There are tow types of assembly in the whole machine assembly, they are step by step assembly and whole assembly. The whole assembly can be used under the condition of less mechanism and simple, all the parts are imported into the assembly drawing and imposed constraints in turn. The characteristics of transplanting mechanism are that components and parts are more, the structure and positional relationship are all relatively complicated, so the type of step by step assembly would be used in this paper. The transmission component with non-circular gear and transplanting component were assembled into sub assembly by the top- down order, and shown in figure 3. The whole machine assembly of transplanting mechanism has been assembled by adding the relevant constraints continuely after the tow components completing, the 3-D virtual prototype model was shown in figure 4 . 


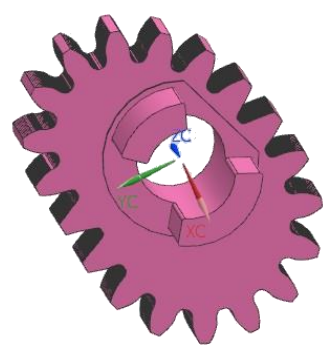

a) Sun gear

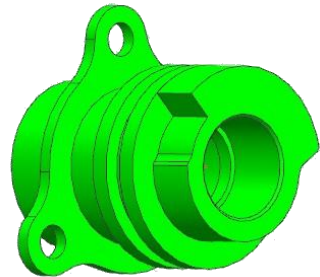

d) $\mathrm{Cam}$

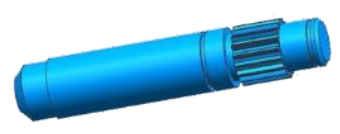

b) Planet shaft

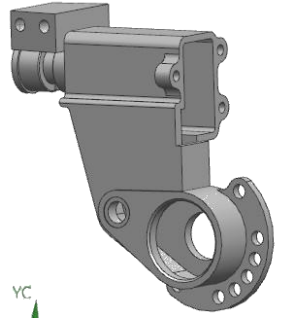

e) Transplanting arm

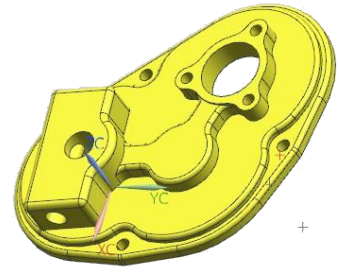

c) Planet carrier

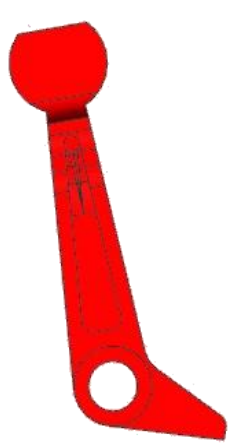

f) Shifting fork

Fig. 2. 3-D models of transplanting parts

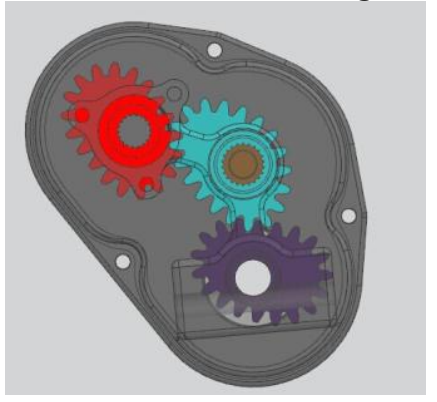

a) Planet carrier

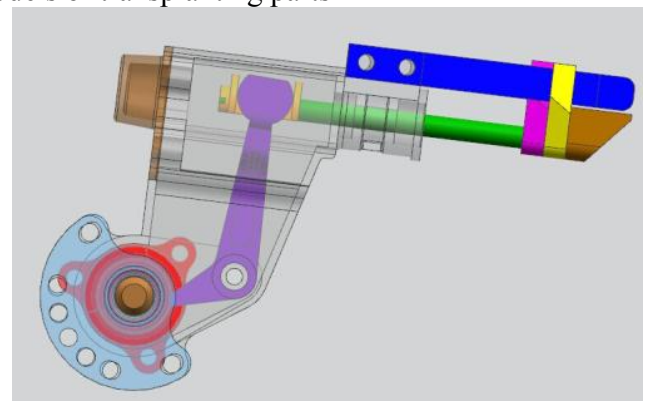

b) Transplanting arm

Fig. 3. Sub assembly of transplanting mechanism

\subsection{Interference Detection}

Based on section of 3.3, each parts and components were related by adding the relevant constraints, but its relationship of mutual cooperation must be checked. In UG the specific methods of interference detection was that, Menu $\rightarrow$ Analysis $\rightarrow$ Examine geometry, check geometrical characteristics of each part in the pop-up menu, and then the system would analyze automatically for transplanting mechanism assembly, the interference detection results were obtained and shown in figure 5. It is know that the whole mechanism without interference from the figure 5. 


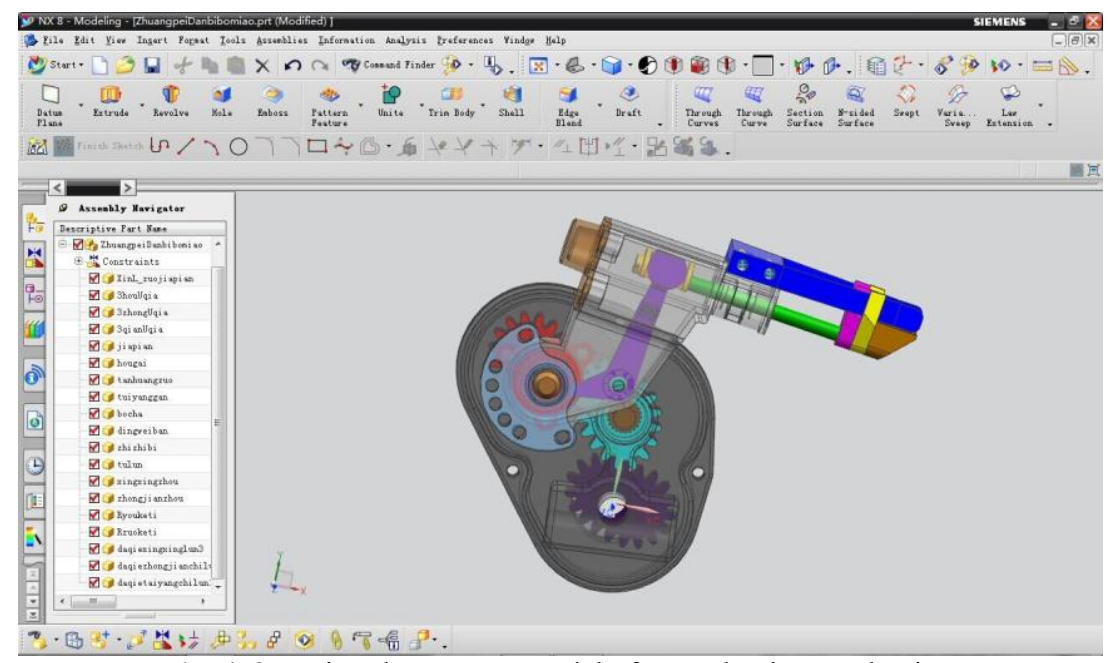

Fig. 4. 3-D virtual prototype model of transplanting mechanism

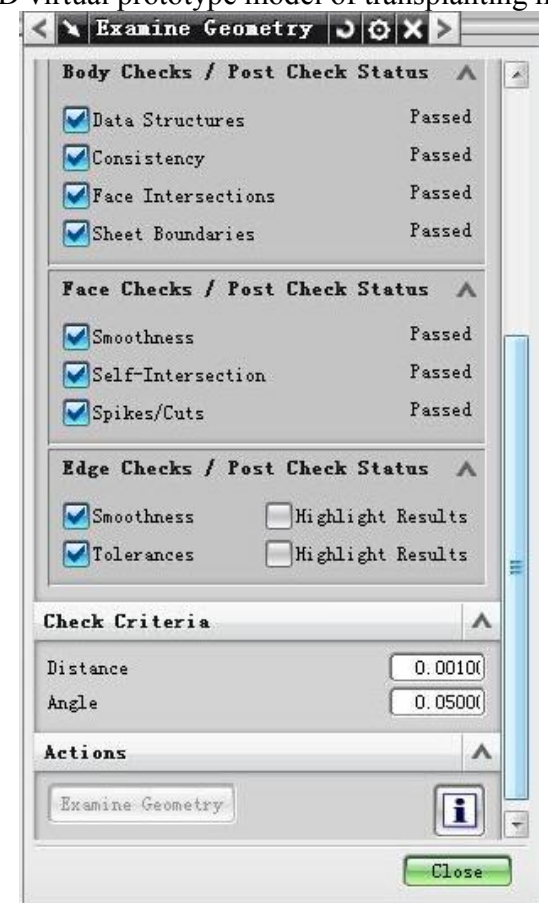

Fig. 5. The interference detection results of virtual prototype

\subsection{Generation of 2-D Engineering Drawings}

Based on above sections, 2-D engineering drawings were generated from corresponding parts and assemblies in the drawing module, and automatic dimensioning was done in each drawing. 3-D models and 2-D engineering drawings 
were related with each other, namely any modification of dimensions made in 3-D part and assembly module would be reflected in drawing module and vice versa, which improving the efficiency. The different angle of projection views, local amplification figure, sectional view and so on, would be produced according to needs in the process of generating 2-D engineering drawings. Some necessary annotations were inserted into drawings as these were required for manufacture, such as weld symbol, geometric tolerance, surface finish symbol, BOM (Bill of Material) and so on. The 2-D assembly drawing was obtained after further processing to the figure 4 , and shown in figure 6 , the $300 \mathrm{~mm}$ is the rice row spacing.

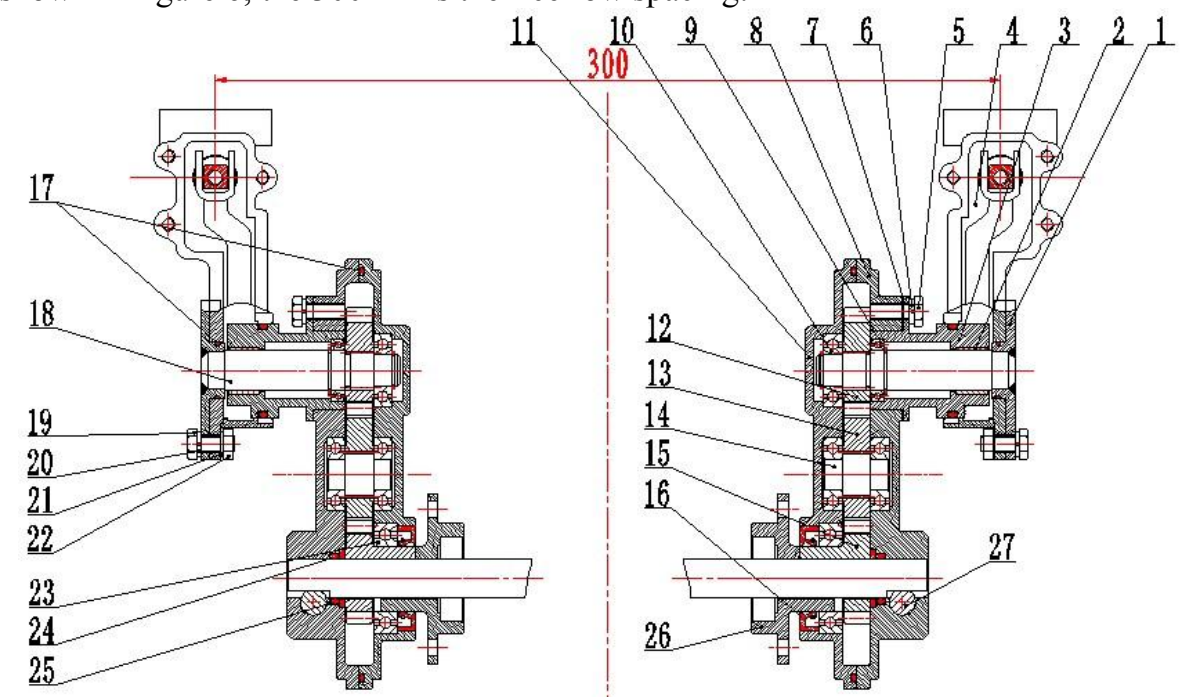

Fig. 6. 2-D assembly drawing of transplanting mechanism

1. Positioning board 2. Cam bushing 3. Cam 4. Transplanting arm 5. Screw 6. Spring washer 7. Packing paper of cam 8. Right shell of planet carrier 9. Circlip 10. Deep groove ball bearing 11. Left shell of planet carrier 12. Planet gear 13. Middle gear 14. Middle shaft 15. Sun gear 16. Skeleton seal ring 17. O seal ring 18. Planet shaft 19. Bolt 20. Elastic washer 21. Flat washer 22. Hex nut 23. Deep groove ball bearing 24. Flat washer 25. O-rubber seal ring 26. Flange 27. Locking pin

\section{Conclusions}

(1)In allusion to the existing rice pot seedling transplanter exists the defects of complex structure, high cost and low efficiency, the necessity of efficient, light simplified and full-automatic was put forward to study on transplanting mechanism for rice pot seedling.

(2)UG NX 8.0 was applied to accomplish parts design, assemblies design, interference detection and generation of 2-D engineering drawings. Results showed that the design was reasonable and feasible.

(3)The created parts and assemblies will be preparation for further simulation and analysis with softwares of Adams and Ansys, it is provides the reference for the design of rice pot seedling transplanter. 


\section{Acknowledgment}

The paper is supported by the National Natural Science Fund Projects (Project number is 51175073), the Special Fund for Agro-scientific Research in the Public Interest (Project number is 201203059-01), the Northeast Agricultural University Doctor Startup Fund (Project number is 2012CRB56).

\section{References}

1. National Bureau of Statistics of the People's Republic of China. China Statistical Yearbook[M]. Beijing: China Statistics Press, 2006. (in Chinese)

2. Yuan Longping. Research Development of Super Hybrid Rice Breeding [J]. China Rice, 2008, (1): 1 3. (in Chinese)

3. Lv Yazhou. Introduction of Development for Rice Transplanting Machine in Our Country[J]. Farm Machinery, 2009, (2): 76-79. (in Chinese)

4. Gao Lianxing, Zhao Xiurong. Effect of Mechanized Transplanting Methods on Rice Yield \& Rice Population Growth Trends. Transactions of the CSAE, 2002, 18: 45-48. (in Chinese)

5. Itou Naokatsu, Shimizu Shunichi, et al. Seedling Transplanting Mechanism of Transplanting Machine[P]. China: ZL 99118740.7. (in Chinese)

6. Yu Lei, Mou Xuelei, Han Xiuhai, et al.. The Application and Development of Rice Pot Seedling Technology[J]. Journal of Agricultural Mechanization Research, 2011, 9: 213-214. (in Chinese)

7. Itou Naokatsu, Shimizu Shunichi, Wata Toshiro, et al. Transplanter [P]. China: ZL200480007602.4. (in Chinese)

8. Onishi Dachiya. New Technique of Rice Cultivation[J]. The Journal of Japanese Soeiety of Agrieultural Maehinery, 1997, 59(4): 123-127. (in Chinese)

9. Kitani Osamu. Agricultural Mechanization in 21st Century [J]. The Journal of Japanese Soeiety of Agrieultural Maehinery, 1997, 59(6): 4-9. (in Chinese)

10. Hu Jianping. The Research of Auto-transplanter's Picking Seedling Mechanism and Seeding Mechanism[EB/OL]. http://www.docin.com/p-280100256.html\#documentinfo. 2011-10-31. (in Chinese)

11. Bing Yanzhong, Chen Zongkai. Development and Application of Mechanization Technology for Rice Pot Seedling Transplanting[J]. Agriculture Machinery Technology Extension, 2011, (4): 52. (in Chinese)

12. Qin Yutian. Rice Practical Cultivation[M]. Beijing: Chinese Agricultural Press, 1984. (in Chinese)

13. Zhao Yun, Xin Liang, Feng Jiang, et al. Transplanting Mechanism of Pot Seedling Transplanting Machine with Double Cranks[P]. China: ZL 201220206603.3. (in Chinese)

14. Ma Qiucheng. The Article of UG-CAE[M]. Beijing: China Machine Press, 2002. (in Chinese) 